\title{
Abstracts presented at the European Association for Osseointegration (EAO) Congresses: Publication fate and discrepancies with fulllength articles
}

DOI:

$10.1111 / \mathrm{clr} .13620$

\section{Document Version}

Accepted author manuscript

Link to publication record in Manchester Research Explorer

Citation for published version (APA):

Wu, X., Yan, Q., Riley, P., Hua, F., Shi, B., Glenny, A., \& Tu, Y. (2020). Abstracts presented at the European Association for Osseointegration (EAO) Congresses: Publication fate and discrepancies with fulllength articles. Clinical Oral Implants Research . https://doi.org/10.1111/clr.13620

Published in:

Clinical Oral Implants Research

\section{Citing this paper}

Please note that where the full-text provided on Manchester Research Explorer is the Author Accepted Manuscript or Proof version this may differ from the final Published version. If citing, it is advised that you check and use the publisher's definitive version.

\section{General rights}

Copyright and moral rights for the publications made accessible in the Research Explorer are retained by the authors and/or other copyright owners and it is a condition of accessing publications that users recognise and abide by the legal requirements associated with these rights.

\section{Takedown policy}

If you believe that this document breaches copyright please refer to the University of Manchester's Takedown Procedures [http://man.ac.uk/04Y6Bo] or contact uml.scholarlycommunications@manchester.ac.uk providing relevant details, so we can investigate your claim.

\section{OPEN ACCESS}




\section{CLINICAL ORAL IMPLANTS RESEARCH WILEY}

\section{Abstracts presented at the European Association for Osseointegration (EAO) Congresses: Publication fate and discrepancies with full-length articles}

\begin{tabular}{|c|c|}
\hline Journal: & Clinical Oral Implants Research \\
\hline Manuscript ID & COIR-Aug-19-OR-7696.R2 \\
\hline Manuscript Type: & Original Research \\
\hline $\begin{array}{r}\text { Date Submitted by the } \\
\text { Author: }\end{array}$ & 25-Feb-2020 \\
\hline Complete List of Authors: & $\begin{array}{l}\text { Wu, Xinyu; School \& Hospital of Stomatology, Wuhan University, The } \\
\text { State Key Laboratory Breeding Base of Basic Science of Stomatology } \\
\text { (Hubei-MOST) \& Key Laboratory for Oral Biomedical Ministry of } \\
\text { Education } \\
\text { Yan, Qi; School \& Hospital of Stomatology, Wuhan University, The State } \\
\text { Key Laboratory Breeding Base of Basic Science of Stomatology (Hubei- } \\
\text { MOST) \& Key Laboratory for Oral Biomedical Ministry of Education } \\
\text { Hua, Fang; School \& Hospital of Stomatology, Wuhan University, Center } \\
\text { for Evidence-Based Stomatology; Division of Dentistry, The University of } \\
\text { Manchester, Cochrane Oral Health } \\
\text { Shi, Bin } \\
\text { Glenny, Anne-Marie; University of Manchester, School of Dentistry } \\
\text { Tu, Yu-Kang; National Taiwan University, Institute of Epidemiology \& } \\
\text { Preventive Medicine, College of Public Health }\end{array}$ \\
\hline Keywords: & Statistics, Clinical research, Clinical trials, Epidemiology \\
\hline
\end{tabular}

\section{SCHOLARONE \\ Manuscripts}




\title{
Abstracts presented at the European Association for Osseointegration (EA0) Congresses: Publication fate and discrepancies with full-length articles
}

\author{
Rinning title : Abstracts presented at the EAO Congresses
}

Xinyu $\mathrm{Wu}^{1,2^{+}}$, Qi Yan ${ }^{1,2^{+}}$, Philip Riley ${ }^{3}$, Fang Hua ${ }^{3,4^{*}}$, Bin Shi ${ }^{*}{ }^{*}$, Anne-Marie Glenny ${ }^{3}$, YuKang Tu ${ }^{5}$

${ }^{1}$ Hubei-MOST KLOS \& KLOBM, School \& Hospital of Stomatology, Wuhan University.

2Department of Oral Implantology, School \& Hospital of Stomatology, Wuhan University.

${ }^{3}$ Cochrane Oral Health, Division of Dentistry, School of Medical Sciences, Faculty of Biology, Medicine and Health, University of Manchester, Manchester Academic Health Science Centre. ${ }^{4}$ Centre for Evidence-Based Stomatology, School \& Hospital of Stomatology, Wuhan University. ${ }^{5}$ Institute of Epidemiology and Preventive Medicine, College of Public Health, National Taiwan University.

${ }^{+}$Xinyu Wu and Qi Yan contributed equally to this work.

\section{* Correspondence}

Fang Hua and Bin Shi. School \& Hospital of Stomatology, Wuhan University, 237

Luoyu Rd, Wuhan 430079, China. Emails: huafang@whu.edu.cn;

shibin_dentist@whu.edu.cn. Tel: 00862787686222.

\section{Acknowledgements}

This work was supported by the National Clinical Key Specialties Construction Project, National Health Commission of China (No. [2013]544), the China Postdoctoral Science Foundation (No. 2018M630884), and the Wuhan Young and Middle-aged Medical Talents Training Program (No. [2019]87).

\section{Author contributions}

Study conception: QY, FH. Study design: XW, QY, FH, BS, PR, AMG. Literature searches: XW, QY, FH. Data Extraction: XW, QY, FH. Data analysis: XW, QY, FH, YKT. Data interpretation: PR, BS, AMG, YKT. Manuscript drafting: $X W, Q Y, F H$. Critical revision of the manuscript: PR, BS, AMG, YKT. Approval of final version: All authors. 


\begin{abstract}
Objectives: To investigate the full publication proportion (FPP) of abstracts presented at the 2010 and 2011 EAO Congresses, analyse the discrepancies between abstracts and their full publications, and explore potential predictors of FPP and discrepancies.

Methods: Abstracts presented at the 2010 and 2011 EAO Congresses were retrieved. Associated full publications were identified by searching PubMed, Embase and Google Scholar. Discrepancies between abstracts and full publications were identified, classified and evaluated using a discrepancy score. The Kaplan-Meier survival analysis was used to describe cumulative FPP over time. Predictors for FPP and the discrepancy score were analysed using cox regression modelling and a linear regression model, respectively.
\end{abstract}

Results: 850 abstracts were included. The overall FPP was $36.4 \%$ with a median time lapse of 12 months. Higher FPP were significantly associated with oral presentation ( $\mathrm{HR}=2.33 ; 95 \% \mathrm{Cl}: 1.68$ to $3.22 ; p<0.001$ ), multiple affiliations ( $\mathrm{HR}=1.32 ; 95 \% \mathrm{Cl}: 1.00$ to $1.73 ; p=0.048)$ and presence of statistical tests ( $\mathrm{HR}=1.78 ; 95 \% \mathrm{Cl}: 1.36$ to 2.32 ; $p<0.001) .91 .3 \%$ pairs had at least one minor change from the abstract and $70.9 \%$ had at least one major change. Greater discrepancy score was significantly associated with longer time lapse $(B=0.06 ; 95 \% \mathrm{Cl}: 0.04$ to $0.08 ; p<0.001)$ and being clinical research ( $B=1.30 ; 95 \% \mathrm{Cl}: 0.52$ to $2.08 ; p=0.001$ ).

Conclusions: Thirty-six percent of abstracts presented at the EAO Congresses were published. Among these, more than two-thirds showed at least one major change in their full publications. Abstracts presented in oral implantology conferences should not be relied upon to inform practice.

Key words: Oral implantology, Publication fate, Discrepancy, Congresses as topic

Word count: 249 (abstract); 3774 (main text) 


\section{Introduction}

The European Association for Osseointegration (EAO) Annual Scientific Congresses, first held in 1992, are an international, interdisciplinary and independent sciencebased forum in oral implantology, attracting thousands of scholars around the world in recent years. An important part of these congresses is to present the most up-todate research in oral implantology, aiming to promote academic communication of researchers and shorten the gap between basic science and clinical practice (Editors, 2003). In 2000, only 62 abstracts were presented at the ninth EAO Congress with about 200 attendees. Ten years later, the 19th EAO congress attracted over 1300 researchers, of whom 408 presented abstracts. Such an increase in the number of abstracts presented at EAO congresses is an indicator of the rapid development of oral implantology research (Sanz et al., 2019).

Conference abstracts are often cited in textbooks (Bhandari et al., 2002) and included in systematic reviews (Cook et al., 1993). However, conference abstracts usually have restrictions on word count, provide inadequate details, lack strict peerreview procedures and some of them only provide preliminary results. Subsequent full-length publication of conference abstracts in peer-reviewed journals can ensure the quality of research, provide details for readers to appraise the validity of studies, and promote the wider dissemination of knowledge (Sprague et al., 2003; Tzanetakis et al., 2018). Therefore, full publication is usually considered the expected outcome of conference presentations and the end point of high-quality research conduct (Kleweno, Bryant, Jacir, Levine, Ahmad, 2008).

Any failure or delay in publishing an abstract in full is unscientific and unethical (Dickersin, Chalmers, 2011), which can lead to reporting and publication biases (Chalmers, Frank, Reitman, 1990; Dickersin, 1990) and amount to a waste of time and resources (Chan et al., 2014). Since 1990, studies have been carried out exploring the full publication proportion (FPP) of abstracts presented at dental conferences (Bagheri et al., 2005; Collier, Vig, Hammond, 2010; Dahllof, Wondimu, Maniere, 2008; Galang et al., 2011; Livas, Pandis, Ren, 2014). Based on a systematic review and meta-analysis of these studies, Hua and colleagues (2016b) found that the pooled overall FPP of dental conference abstracts was $29.6 \%$, and that factors including presentation type, study type, significance of results, sample size and industry funding were significantly 
associated with FPP. However, the publication outcome of abstracts presented at oral implantology conferences has not been studied.

In addition, discrepancies between conference abstracts and full publications can result in reporting and publication biases (Chalmers et al., 1990; van den Bogert et al., 2017), thus leading to concerns over whether conference abstracts should be included in systematic reviews (Saldanha, Scherer, Rodriguez-Barraquer, Jampel, Dickersin, 2016). Previous studies have shown that discrepancies with the corresponding full articles ranged from 19\% to $96 \%$ of conference abstracts (Denadai et al., 2016; Li et al., 2017; Prasad et al., 2012; Rosmarakis, Soteriades, Vergidis, Kasiakou, Falagas, 2005) depending on subject area and time lapse (defined as time taken from abstract presentation to full publication) (Rosmarakis et al., 2005; Saric et al., 2019). To our best knowledge, the discrepancies between conference abstracts in oral implantology and their full-length articles have not been investigated in the literature.

Therefore, the objectives of this study were: (1) to estimate the FPP of abstracts presented at the 2010 and 2011 EAO Congresses; (2) to investigate the discrepancies between these abstracts and their subsequent full publications; and ( 3 ) to explore potential predictors of FPP and the level of discrepancies.

\section{Materials and methods}

2.1 Retrieval of abstracts and full publications

All abstracts presented at the 2010 and 2011 EAO Congresses were retrieved from the online archive of Clinical Oral Implants Research (onlinelibrary.wiley.com/journal/16000501). Structured abstracts reporting original research were included. Thereafter, three authors (X.W., Q.Y. and F.H.) searched PubMed, Embase and Google Scholar for full publications of the included abstracts. No restriction was set on language. The last search was conducted on 30/11/2018. The initial search terms included the full title of abstract and name of the first author. If no corresponding full publication was identified, an additional search was carried out using the family name of the first / second / last author combined with key words / phrases from the abstract title. As determined a priori, a match was considered when the identified full article had the same objectives, interventions and study design, a similar title, and shared the same main authors (judging by names and affiliations). If 
more than one full article were identified for the same abstract, the article with the shortest time lapse was included.

\subsection{Data extraction}

The following characteristics of each identified abstract were collected by two authors independently and in duplicate: (1) presentation type (oral or poster), (2) study type (basic research or clinical study), (3) study design (RCT, CCT, others), (4) number of authors, (5) continent of the first author, (6) multiple affiliations, (7) international collaboration, (8) presence of statistical tests, and (9) presence of significant results. Any disagreement was resolved through discussion.

In addition, for the identified full publications, their PMID and DOI, online publication date, journal name, time lapse and funding sources (funded by industry, funded by other sources, or unfunded/unreported) were recorded. All disagreements were resolved through discussion.

\subsection{Evaluation of discrepancies}

Discrepancies between the abstracts and full publications were classified into two types of minor changes (title, authorship) and nine types of major changes (objectives, interventions, type of statistical test used, outcome measures, primary outcome, sample size, quantitative results, statistical significance and conclusions). If relevant information was not provided in an abstract, the corresponding types of changes were documented as "unreported". Table 1 lists the detailed definition for each type of change. To quantify the severity of discrepancy, each minor change was scored one point and each major change was scored two points. A discrepancy score was then calculated by totalling all points for minor and major changes for each abstract (score range: 0-20). For RCTs and CCTs, changes in their registration ID, use of blinding, follow-up length and reported harms were also recorded. Two authors (X.W. and Q.Y.) evaluated the aforementioned discrepancies independently and in duplicate, with all disagreements resolved through discussions.

\subsection{Statistical analysis}

SPSS version 25 (IBM Corp, Armonk, NY, USA) was used for descriptive data and statistical analyses. The Kaplan-Meier survival analysis was used to describe the 72- 
month cumulative FPP. Full articles published before conference presentation were excluded from survival analyses. Association between each abstract characteristic and the FPP over time was analysed first with univariable log rank tests. Proportional hazard assumption was evaluated using a graphic check, reflected by separate lines in a contemporary log plot. Then, significant characteristics in log rank tests $(p<0.05)$ were further analysed with multivariable cox regression modelling. Additionally, to explore the predictors of discrepancies, linear regression analyses were performed. Independent variables included time lapse, financial support and the eight abstract characteristics (presentation type, study type, number of authors, continent of the first author, multiple affiliations, international collaboration, presence of statistical tests, significance of results.), while the dependent variable was discrepancy score. Each potential predictor was initially fitted in univariable linear regression analyses; thereafter, all significant predictors $(p<0.05)$ in the univariable analyses were entered into the multivariable analysis. Residuals in linear regression models did not show significant violation of normality.

\subsection{Ancillary analysis}

To test the robustness of our findings based on the discrepancy score, an ancillary analysis was conducted by setting the number of all discrepancies (including both minor and major discrepancies) as the dependent variable and repeating the linear regression analyses described above.

\section{Results}

\subsection{FPP and time lapse}

Overall, 850 abstracts presented at the 2010 and 2011 EAO Congresses were recorded, the characteristics of which are listed in Table 2. A total of 309 full publications were identified, indicating an FPP of 36.4\%. The FPP for RCTs and CCTs were 66.1\% (41/62) and $43.3 \%$ (74/171), respectively (Table 3). The median time lapse was 12 months, with the inter-quantile range being 1 to 24 months (Figure 1a). Seventeen percent $(53 / 309)$ of the full publications were published before conference presentation and $81.5 \%(252 / 309)$ of the full publications were published within five years after 
conference presentation.

\subsection{Predictors for cumulative FPP over time}

Fifty-three abstracts had full publications before conferences and were excluded from survival analyses and cox regression modelling. According to Kaplan-Meier survival analyses, significant association was found between higher FPP and being oral presentation $(p<0.001)$, international collaboration $(p<0.001)$, presence of statistical test $(p<0.001)$, multiple affiliations $(p<0.001)$, basic research $(p=0.029)$, more authors $(p=0.001)$, authors from Europe $(p=0.036)$, and significant results $(p<0.001)$. Proportional hazard assumption was valid in presentation type, international collaboration, presence of statistical test, multiple affiliations, and study type. These characteristics were then entered into a multivariable Cox regression model which suggested that presentation type (hazard ratio $[\mathrm{HR}]=2.33 ; 95 \% \mathrm{Cl}: 1.68$ to 3.22 ; $p<0.001)$, multiple affiliations ( $\mathrm{HR}=1.32 ; 95 \% \mathrm{Cl}: 1.00$ to $1.73 ; p=0.048)$ and statistical test $(\mathrm{HR}=1.78 ; 95 \% \mathrm{Cl}: 1.36$ to $2.32 ; p<0.001)$ remained significant (Figure 1 ).

\subsection{Pattern of discrepancies}

Discrepancies occurred in $95.1 \%$ pairs of abstracts and full articles. The median number of discrepancies per pair was 3 (inter-quantile range: 2 to 4). The mean discrepancy score was 4.9 (standard deviation 3.5). 91.3\% pairs had at least one minor change and $70.9 \%$ pairs had at least one major change.

For minor changes, discrepancies in authorship (73.5\%) and title (71.8\%) were relatively common. For major changes, discrepancies in quantitative results $(56.8 \%)$ were the most prevalent. Of 96 pairs that had changes in sample size, 8.3\% (8/96) had the same quantitative results while $13.5 \%$ (13/96) changed their statistical significance.

$19.0 \%$ (34/309) pairs had discrepancies in the statistical significance of results, among which $5.2 \%$ pairs (16/309) had changes pertaining to statistical significance for more than one outcome. The results of half of these pairs (17/34) changed from being non-significant to significant while the other half from being significant to nonsignificant. $50 \%$ pairs $(17 / 34)$ had discrepancies in conclusions.

In addition, 8 pairs of abstracts and full-texts had different sample sizes but the same quantitative results (in 8 pairs). Four pairs had the same quantitative results but reported different statistical significance. 
For incomplete reporting, 99.4\% (307/309) pairs provided insufficient data for at least one discrepancy category, which made the corresponding comparison impossible. Information about which variable was the primary outcome was missing in $96.8 \%$ (299/309) pairs while methods of statistical analysis were unreported in $71.2 \%$ (220/309) pairs (Table 4).

In addition, the pattern of specific discrepancy categories for RCTs and CCTs are listed in Table 5. Discrepancies were found in reported harms (40.9\%) and follow-up length (18.5\%).

\subsection{Predictors of discrepancies}

According to univariable analyses, longer time lapse, being clinical study, and having a first author from Europe or South America were all significantly associated with greater discrepancy score. However, only time lapse $(B=0.06 ; 95 \% \mathrm{Cl}: 0.04$ to 0.08 ; $p<0.001)$ and study type $(B=1.30 ; 95 \% \mathrm{Cl}: 0.52$ to $2.08 ; p=0.001)$ remained significant in the multivariable linear regression (Table 6). Results of our ancillary analysis also suggested that time lapse $(B=0.04 ; 95 \% \mathrm{Cl}: 0.02$ to $0.05 ; p<0.001)$ and study type $(B=0.66 ; 95 \% \mathrm{Cl}: 0.26$ to $1.08 ; p=0.002)$ were significant predictors of the number of discrepancies (Table 7).

\section{Discussion}

To our knowledge, this is the first attempt to formally evaluate the publication fate and discrepancies of abstracts presented at EAO Congresses. In the 2010 and 2011 EAO Congresses, $36.4 \%$ abstracts were published in full, with a median time lapse of 12 months. Cumulative FPP over time was significantly associated with presentation type, multiple affiliations and presence of statistical test. Discrepancies between abstract and full publications were found in $95.1 \%$ pairs. The severity of discrepancy was significantly associated with time lapse and study type.

\subsection{FPP and time lapse}

In this study, FPP for EAO Congress abstracts was slightly higher than that reported previously (29.6\%) for dental conferences (Hua et al., 2016b). On the one hand, higher FPP could reflect higher quality of a conference (Toma et al., 2006). Abstracts 
presented at high-quality conferences such as the EAO Congresses, are subject to strict review process, high acceptance standard and emphasis on clinical significance before being presented at conferences, and should therefore be more successful in the competition for space in academic journals (Schulte et al., 2012). On the other hand, oral implantology is a unique area in dentistry in that it attracts the attention of prosthodontists, periodontists and oral surgeons. As a result, authors of papers in oral implantology usually have more options when selecting which journals to submit to than papers in other fields. In addition, FPP has been found to be associated with methodological aspects such as type of study included (all study types or only RCTs) (Hua et al., 2016b). In this study, the FPP of RCTs (66.1\%) was nearly twice as high as that of all study types (36.4\%). This was in accordance with previous studies that reported a higher FPP of RCTs than that of other studies (Dahllof et al., 2008; Moar, Butterworth, 2013; Scherer et al., 2018). Thus, the proportion of RCTs in conference abstracts might also have an impact on FPP.

Of abstracts presented at the 2010 and 2011 EAO Congresses, almost two-thirds were not published. According to a recent systematic review (Scherer, Ugarte-Gil, Schmucker, Meerpohl, 2015), the most frequent and important reason for not publishing abstracts was the lack of time. Other reasons included lack of resources, publication not being an aim, and low priority.

In this study, the median time lapse was 12 months and $98.4 \%$ full articles were published within five years. This was in accordance with previous studies that a fiveyear time lapse was an enough follow-up length of publication fate studies (Bagheri et al., 2005; Scholey, Harrison, 2005). Excessive delay of full publication makes research findings obsolete and reduces available evidence, thus causing publication bias (Scholey, Harrison, 2003).

Notably, in our study, almost $60 \%$ conference abstracts did not mention any statistical test (Table 2). It is unclear whether the authors of these abstracts did not perform any statistical test, or they chose not to report the corresponding analyses and results in their conference abstracts. Nevertheless, this may be another indicator that abstracts presented at EAO are of limited methodological quality, as high-quality studies usually adopt and formal statistical analyses to test research hypotheses, and report their results and conclusion based on such analyses. 


\subsection{Pattern of discrepancies}

In this study, at least one type of change occurred in $95.1 \%$ pairs. Although slight differences in discrepancy categories existed across studies, our findings were similar with previous studies on dental conferences, which reported 95.6\% (Prasad et al., 2012) and 89\% (Yuan et al., 2011) discrepancies, respectively.

Major discrepancies in results, including quantitative outcomes $(56.8 \%)$, sample size (35\%) and statistical significance (19.0\%), were common. The increase in sample size could be explained by ongoing studies. However, the decrease in sample size was problematic, especially when no explanation was provided (Kleweno et al., 2008). Interestingly, 42 pairs in our sample had a decrease in sample size but none of them provided any explanation. Reason behind this phenomenon is unclear and may be explored in future research. One measure that journal editors may consider is to require authors to report any previous conference presentation of the study in their manuscripts (e.g. in the acknowledgements section). In this way, editors and peer reviewers are able to make comparisons, identify potential problems (such as a decrease in sample size) and ask for necessary explanations.

Thirty-four pairs had discrepancies in result significance. The results of half of these pairs (17/34) changed from being non-significant to significant while the other half from being significant to non-significant. This finding contradicted previous research which stated that studies with significant results are more likely to be published, because authors are usually reluctant to submit their research with nonsignificant results (Riordan, 2000; Sprague et al., 2003). One explanation for our finding is that bias occurred before conference (Song et al., 2009). In a systematic review, Song and colleagues (2009) reported that publication bias mainly occurred before abstract presentation at conferences. The extent of bias tended to be smaller in subsequent publications. Another explanation was information gain (the extent to which new knowledge changes previous perceptions) (Evangelou, Siontis, Pfeiffer, loannidis, 2012). If the change in statistical significance of results from a study could change current knowledge, the study is more likely to publish.

Conference abstracts should be submitted in a standard format to provide key information. In the 2010 and 2011 EAO Congresses, almost all abstracts suffered from poor reporting (providing insufficient information for at least one category), which 
was in keeping with the results of a previous study regarding abstracts in orthodontic conferences (Hua, Walsh, Glenny, Worthington, 2016a). Changed or ambiguous methods could lead to changed result significance and direction of conclusions (Chan, Altman, 2005; Chan, Hrobjartsson, Haahr, Gotzsche, Altman, 2004; Grant, Booth, Khodyakov, 2018; Williamson, Gamble, Altman, Hutton, 2005). Thus, a pre-defined and consistent method is important for preventing selective reporting and ensuring the quality of research (Greenberg, Jairath, Pearse, Kahan, 2018). In addition, missing information makes it difficult for readers to judge the quality of abstracts for further interpretation and application. Although abstracts usually have limitations on word count, a structured abstract is recommended to make key information available. For instance, a previous study (Hua, Walsh, Glenny, Worthington, 2018) found that highly structured abstracts were better reported than those in the IMRaD format, therefore the authors developed a 12-heading highly structured format for reporting RCT abstracts. In addition, it may be preferable if abstracts could be subject to more rigorous evaluation before being admitted to presentation. Clinicians are recommended to read full publications to obtain comprehensive details (Richards, 2005).

\subsection{Predictors of FPP and discrepancies}

In the present study, several predictors of FPP over time were identified, including oral presentation, multi-affiliation and presence of statistical test.

Result significance was not a significant predictor for FPP, which contradicted previous studies in dentistry and medicine (Galang et al., 2011; Lee et al., 2012; Livas et al., 2014; Saldanha et al., 2016). Some methodological studies suggested that significant results were usually considered important and were more likely to be published in high-impact journals and attract more citations (Dickersin, 1990; Dickersin, Min, Meinert, 1992; Duyx, Urlings, Swaen, Bouter, Zeegers, 2017; Easterbrook, Berlin, Gopalan, Matthews, 1991). However, in this study, no association was found between FPP over time and the significance of results. One potential explanation for this is the variation among different subjects. In a systematic review investigating all types of scientific meetings, association was found between significance of results and FPP (Scherer et al., 2018). Whereas in a systematic review regarding dental conferences no such association was found (Hua et al., 2016b). 
Another explanation for our finding is that publication bias presents differently at different stages (Hua et al., 2016b; Song et al., 2009). Nowadays more journals are open to manuscripts with non-significant or null results, which could help reduce publication bias associated with result significance.

In this study, the discrepancy score was used to quantify the level of discrepancies. Discrepancy score not only considered every category of discrepancies, but also distinguished the impact of major changes from minor changes. Discrepancy score was significantly associated with time lapse and being clinical study. Longer time lapse leaves authors enough time to complete and modify their research, meanwhile resulting in discrepancies. Being clinical studies was also associated with higher discrepancy score. Comparing with basic research, clinical studies usually reported preliminary results, had more uncontrollable factors, incurred more expenses and faced more difficulties in execution (Scherer et al., 2018). For systematic reviewers, sensitivity analysis is recommended if conference abstracts are included (Saric et al., 2019). Combining pattern of discrepancies and the significant predictors, it is suggested that abstracts initially presented at conference are not guaranteed for validity and reliability and should be interpreted or applied with caution.

\subsection{Strengths and limitations}

The strength of this study lies in: (1) a comprehensive literature search and a large sample size; (2) application of cox regression modelling to investigate potential predictors for FPP over time; (3) a detailed and intelligible categorization and quantitative evaluation of discrepancies; (4) using discrepancy score as dependent variable to investigate predictors for severity of discrepancies in a linear regression model. This study provides empirical evidence for the EAO committee to plan for future meetings, revise the submission and review criteria for abstracts, and thereby promote a clearer and more reliable academic exchange.

However, our study has some limitations. Firstly, some crucial information was missing from abstracts. This might underestimate the severity of discrepancies. Secondly, some full publications might be omitted. The EAO Congresses did not provide e-mail of abstract corresponding authors thus it was impossible to contact every author to identify all the full publications. However, our comprehensive literature search reflected the situation in which readers searched for full publications. 
Thus, the present study is of practical significance. Thirdly, only abstracts presented at 2010 and 2011 EAO Congresses were evaluated. No comparison among different conferences or time points were made. The publication fate of other conferences in oral implantology or its temporal trend could be analysed in future studies. Regarding the rapid development of oral implantology, we will keep focusing on the EAO Congress and investigate the conversion from abstracts to full publications.

\section{Conclusions}

- Only about one-third of abstracts presented at the EAO Congresses were published in full. Abstracts presented orally, with multiple affiliations or statistical tests were more likely to be published.

- Among those published, more than two-thirds had at least one major discrepancy with the corresponding full articles. The severity of discrepancies between abstracts and full articles was significantly associated with longer time lapse and being clinical research.

- In light of these findings, abstracts presented in the EAO Congresses should not be relied upon to inform practice. 


\section{References}

Bagheri, S. C., Lenox, N., Verschueren, D. S., Holmgren, E., Kademani, D., Bell, R. B., \& Dierks, E. J. (2005). Abstracts from the American Association Of Oral And Maxillofacial Surgeons annual scientific meeting: proportion published and time to publication. Journal of Oral and Maxillofacial Surgery, 63, 838-840. doi:10.1016/j.joms.2005.02.020

Bhandari, M., Devereaux, P. J., Guyatt, G. H., Cook, D. J., Swiontkowski, M. F., Sprague, S., \& Schemitsch, E. H. (2002). An observational study of orthopaedic abstracts and subsequent full-text publications. Journal of Bone and Joint Surgery - American Volume, 84-A, 615-621. doi:10.2106/00004623-200204000-00017

Chalmers, T. C., Frank, C. S., \& Reitman, D. (1990). Minimizing the three stages of publication bias. The Journal of American Medical Association, 263, 1392-1395. doi:10.1001/jama.1990.03440100104016

Chan, A. W., \& Altman, D. G. (2005). Identifying outcome reporting bias in randomised trials on PubMed: review of publications and survey of authors. British Medical Journal, 330, 753. doi:10.1136/bmj.38356.424606.8F

Chan, A. W., Hrobjartsson, A., Haahr, M. T., Gotzsche, P. C., \& Altman, D. G. (2004). Empirical evidence for selective reporting of outcomes in randomized trials: comparison of protocols to published articles. The Journal of American Medical Association, 291, 2457-2465. doi:10.1001/jama.291.20.2457

Chan, A. W., Song, F. J., Vickers, A., Jefferson, T., Dickersin, K., Gotzsche, P. C., Krumholz, H. M., Ghersi, D., \& van der Worp, H. B. (2014). Increasing value and reducing waste: addressing inaccessible research. Lancet, 383, 257-266. doi:10.1016/S0140-6736(13)62296-5

Collier, J. M., Vig, N., \& Hammond, D. (2010). Publish or perish? A survey of abstracts accepted for meetings of the British Association of Oral and Maxillofacial Surgeons, and subsequently published. British Journal of Oral and Maxillofacial Surgery, 48, 540-543. doi:10.1016/j.bjoms.2009.08.037

Cook, D. J., Guyatt, G. H., Ryan, G., Clifton, J., Buckingham, L., Willan, A., Mcllroy, W., \& Oxman, A. D. (1993). Should unpublished data be included in meta-analyses? Current convictions and controversies. The Journal of American Medical Association, 269, 2749-2753. doi:10.1001/jama.1993.03500210049030

Dahllof, G., Wondimu, B., \& Maniere, M. C. (2008). Subsequent publication of abstracts presented at the International Association of Paediatric Dentistry meetings. International Journal of Paediatric Dentistry, 18, 91-97. doi:10.1111/j.1365-263X.2007.00898.x

Denadai, R., Araujo, G. H., Pinho, A. S., Denadai, R., Samartine, H., Jr., \& Raposo-Amaral, C. E. (2016). Discrepancies Between Plastic Surgery Meeting Abstracts and Subsequent Full-Length Manuscript Publications. Aesthetic plastic surgery, 40, 778-784. doi:10.1007/s00266-016-0680-3

Dickersin, K. (1990). The existence of publication bias and risk factors for its occurrence. The Journal of American Medical Association, 263, 1385-1389. doi:10.1001/jama.263.10.1385

Dickersin, K., \& Chalmers, I. (2011). Recognizing, investigating and dealing with incomplete and biased reporting of clinical research: from Francis Bacon to the WHO. Journal of the Royal Society of Medicine, 104, 532-538. doi:10.1258/jrsm.2011.11k042

Dickersin, K., Min, Y. I., \& Meinert, C. L. (1992). Factors influencing publication of research results. Follow-up of applications submitted to two institutional review boards. The Journal of American Medical Association, 267, 374-378. doi:10.1001/jama.1992.03480210049019

Duyx, B., Urlings, M. J. E., Swaen, G. M. H., Bouter, L. M., \& Zeegers, M. P. (2017). Scientific citations favor positive results: a systematic review and meta-analysis. Journal of Clinical Epidemiology, 88, 92-101. doi:10.1016/j.jclinepi.2017.06.002

Easterbrook, P. J., Berlin, J. A., Gopalan, R., \& Matthews, D. R. (1991). Publication bias in clinical research. Lancet, 337, 867-872. doi:10.1016/0140-6736(91)90201-Y

Editors, T. (2003). EAO European Association For Osseointegration. Clinical oral implants research, 14, 512-512. doi:10.1034/j.1600-0501.2003.t01-1-01010.x

Evangelou, E., Siontis, K. C., Pfeiffer, T., \& loannidis, J. P. (2012). Perceived information gain from randomized trials correlates with publication in high-impact factor journals. Journal of Clinical Epidemiology, 65, 1274-1281. 
Galang, M. T., Yuan, J. C., Lee, D. J., Barao, V. A., Shyamsunder, N., \& Sukotjo, C. (2011). Factors influencing publication rates of abstracts presented at the ADEA annual session \& exhibition. Journal of Dental Education, 75, 549-556.

Grant, S., Booth, M., \& Khodyakov, D. (2018). Lack of preregistered analysis plans allows unacceptable data mining for and selective reporting of consensus in Delphi studies. Journal of Clinical Epidemiology, 99, 96-105. doi:10.1016/j.jclinepi.2018.03.007

Greenberg, L., Jairath, V., Pearse, R., \& Kahan, B. C. (2018). Pre-specification of statistical analysis approaches in published clinical trial protocols was inadequate. Journal of Clinical Epidemiology, 101, 53-60. doi:10.1016/j.jclinepi.2018.05.023

Hua, F., Walsh, T., Glenny, A. M., \& Worthington, H. (2016a). Reporting quality of randomized controlled trial abstracts presented at European Orthodontic Society congresses. European journal of orthodontics, 38 , 584-592. doi:10.1093/ejo/cjv094

Hua, F., Walsh, T., Glenny, A. M., \& Worthington, H. (2016b). Thirty percent of abstracts presented at dental conferences are published in full: a systematic review. Journal of Clinical Epidemiology, 75, 16-28. doi:10.1016/j.jclinepi.2016.01.029

Hua, F., Walsh, T., Glenny, A. M., \& Worthington, H. (2018). Structure formats of randomised controlled trial abstracts: a cross-sectional analysis of their current usage and association with methodology reporting. BMC Medical Research Methodology, 18, 6. doi:10.1186/s12874-017-0469-3

Kleweno, C. P., Bryant, W. K., Jacir, A. M., Levine, W. N., \& Ahmad, C. S. (2008). Discrepancies and rates of publication in orthopaedic sports medicine abstracts. Amrican Journal of Sports Medicine, 36, 1875-1879. doi:10.1177/0363546508319054

Lee, D. J., Yuan, J. C., Prasad, S., Barao, V. A., Shyamsunder, N., \& Sukotjo, C. (2012). Analysis of abstracts presented at the prosthodontic research section of IADR General Sessions 2004-2005: demographics, publication rates, and factors contributing to publication. Journal of Prosthodontics, 21, 225-231. doi:10.1111/j.1532-849X.2011.00792.x

Li, G., Abbade, L. P. F., Nwosu, I., Jin, Y., Leenus, A., Maaz, M., Wang, M., Bhatt, M., Zielinski, L., Sanger, N., Bantoto, B., Luo, C., Shams, I., Shahid, H., Chang, Y., Sun, G., Mbuagbaw, L., Samaan, Z., Levine, M. A. H., Adachi, J. D., \& Thabane, L. (2017). A scoping review of comparisons between abstracts and full reports in primary biomedical research. BMC Medical Research Methodology, 17, 181. doi:10.1186/s12874-017-0459-5

Livas, C., Pandis, N., \& Ren, Y. (2014). Full-text publication of abstracts presented at European Orthodontic Society congresses. European journal of orthodontics, 36, 569-575. doi:10.1093/ejo/cjt089

Moar, K., \& Butterworth, S. (2013). If you present will you publish? An analysis of abstracts at the craniofacial society of great britain and ireland conferences 2000-2009. The Cleft Palate-Craniofacial Journal, 50, 713716. doi:10.1597/12-335

Prasad, S., Lee, D. J., Yuan, J. C., Barao, V. A., Shyamsunder, N., \& Sukotjo, C. (2012). Discrepancies between Abstracts Presented at International Association for Dental Research Annual Sessions from 2004 to 2005 and Full-Text Publication. International Jounal of Dentistry, 2012, 859561. doi:10.1155/2012/859561

Richards, D. (2005). All in the spin. Evidence Based Dentistry, 6, 29-30. doi:10.1038/sj.ebd.6400330

Riordan, F. A. (2000). Do presenters to paediatric meetings get their work published? Archives of Disease in Childhood, 83, 524-526. doi:10.1136/adc.83.6.524

Rosmarakis, E. S., Soteriades, E. S., Vergidis, P. I., Kasiakou, S. K., \& Falagas, M. E. (2005). From conference abstract to full paper: differences between data presented in conferences and journals. The FASEB Journal, 19, 673-680. doi:10.1096/fj.04-3140lfe

Saldanha, I. J., Scherer, R. W., Rodriguez-Barraquer, I., Jampel, H. D., \& Dickersin, K. (2016). Dependability of results in conference abstracts of randomized controlled trials in ophthalmology and author financial conflicts of interest as a factor associated with full publication. Trials, 17, 213. doi:10.1186/s13063-016-1343-z

Sanz, M., Noguerol, B., Sanz-Sanchez, I., Hammerle, C. H. F., Schliephake, H., Renouard, F., Sicilia, A., Steering, C., Cordaro, L., Jung, R., Klinge, B., Valentini, P., Alcoforado, G., Ornekol, T., Pjetursson, B., Sailer, I., Rochietta, 
I., Manuel Navarro, J., Heitz-Mayfield, L., \& Francisco, H. (2019). European Association for Osseointegration Delphi study on the trends in Implant Dentistry in Europe for the year 2030. Clinical oral implants research, 30, 476-486. doi:10.1111/clr.13431

Saric, L., Vucic, K., Dragicevic, K., Vrdoljak, M., Jakus, D., Vuka, I., Jelicic Kadic, A., Saldanha, I. J., \& Puljak, L. (2019). Comparison of conference abstracts and full-text publications of randomized controlled trials presented at four consecutive World Congresses of Pain: Reporting quality and agreement of results. European Journal of Pain, 23, 107-116. doi:10.1002/ejp.1289

Scherer, R. W., Meerpohl, J. J., Pfeifer, N., Schmucker, C., Schwarzer, G., \& von Elm, E. (2018). Full publication of results initially presented in abstracts. Cochrane Database of Systematic Reviews, 11, MR000005. doi:10.1002/14651858.MR000005.pub4

Scherer, R. W., Ugarte-Gil, C., Schmucker, C., \& Meerpohl, J. J. (2015). Authors report lack of time as main reason for unpublished research presented at biomedical conferences: a systematic review. Journal of Clinical Epidemiology, 68, 803-810. doi:10.1016/j.jclinepi.2015.01.027

Scholey, J. M., \& Harrison, J. E. (2003). Publication bias: raising awareness of a potential problem in dental research. British Dental Journal, 194, 235-237. doi:10.1038/sj.bdj.4809923

Scholey, J. M., \& Harrison, J. E. (2005). Delay and failure to publish dental research. Evidence Based Dentistry, 6, 58-61. doi:10.1038/sj.ebd.6400347

Schulte, T. L., Huck, K., Osada, N., Trost, M., Lange, T., Schmidt, C., Gosheger, G., \& Bullmann, V. (2012). Publication rate of abstracts presented at the Annual Congress of the Spine Society of Europe (years 2000-2003). European Spine Journal, 21, 2105-2112. doi:10.1007/s00586-012-2211-5

Song, F., Parekh-Bhurke, S., Hooper, L., Loke, Y. K., Ryder, J. J., Sutton, A. J., Hing, C. B., \& Harvey, I. (2009). Extent of publication bias in different categories of research cohorts: a meta-analysis of empirical studies. BMC Medical Research Methodology, 9, 79. doi:10.1186/1471-2288-9-79

Sprague, S., Bhandari, M., Devereaux, P. J., Swiontkowski, M. F., Tornetta, P., 3rd, Cook, D. J., Dirschl, D., Schemitsch, E. H., \& Guyatt, G. H. (2003). Barriers to full-text publication following presentation of abstracts at annual orthopaedic meetings. Journal of Bone and Joint Surgery-Amrican Volume, 85-A, 158-163. doi:10.1021/cen-v079n026.p010a

Toma, M., McAlister, F. A., Bialy, L., Adams, D., Vandermeer, B., \& Armstrong, P. W. (2006). Transition from meeting abstract to full-length journal article for randomized controlled trials. The Journal of American Medical Association, 295, 1281-1287. doi:10.1001/jama.295.11.1281

Tzanetakis, G. N., Tzimpoulas, N., Floratos, S., Agrafioti, A., Kontakiotis, E. G., \& Shemesh, H. (2018). Full-text publication rates of research abstracts presented at the European Society of Endodontology congresses in the last 20 years. International Endodontic Journal, 51, 215-222. doi:10.1111/iej.12805

van den Bogert, C. A., Souverein, P. C., Brekelmans, C. T. M., Janssen, S. W. J., Koeter, G. H., Leufkens, H. G. M., \& Bouter, L. M. (2017). Primary endpoint discrepancies were found in one in ten clinical drug trials. Results of an inception cohort study. Journal of Clinical Epidemiology, 89, 199-208. doi:10.1016/j.jclinepi.2017.05.012

Williamson, P. R., Gamble, C., Altman, D. G., \& Hutton, J. L. (2005). Outcome selection bias in meta-analysis. Statistical Methods in Medical Research, 14, 515-524. doi:10.1191/0962280205sm415oa

Yuan, J. C., Galang, M. T., Lee, D. J., Barao, V. A., Shyamsunder, N., \& Sukotjo, C. (2011). Differences between ADEA Annual Session poster abstracts and their corresponding full published articles. Jounal of Dental Education, 75, 1476-1481. doi:10.1111/j.1600-051X.2011.01786.x 
Table 1 The definition used in this study for each type of discrepancy.

\begin{tabular}{|c|c|c|}
\hline Severity & Type & Definition \\
\hline \multirow[t]{2}{*}{$\begin{array}{l}\text { Minor } \\
\text { change }\end{array}$} & Title & $\begin{array}{l}\text { Any change in title, except for adding or deleting of no more than } \\
\text { three words or change of word order. }\end{array}$ \\
\hline & Authorship & Any change in first author or number of authors. \\
\hline \multirow{9}{*}{$\begin{array}{l}\text { Major } \\
\text { change }\end{array}$} & Objectives & Addition, deletion or replacement of objective items. \\
\hline & Intervention & $\begin{array}{l}\text { Any change of methods in participant selection, group allocation, } \\
\text { surgery and restoration procedure (for clinical studies) or } \\
\text { experimental methods (for basic research). }\end{array}$ \\
\hline & $\begin{array}{l}\text { Outcome } \\
\text { measures }\end{array}$ & $\begin{array}{l}\text { Addition, deletion or replacement of specific outcome measures. } \\
\text { When outcome measures are not described specifically, for } \\
\text { example "clinical index" rather than "attachment loss", } \\
\text { "bleeding on probing" or "pocked depth", we define it "not } \\
\text { reported". }\end{array}$ \\
\hline & $\begin{array}{l}\text { Type of } \\
\text { statistical test } \\
\text { used }\end{array}$ & $\begin{array}{l}\text { Any change in key statistical analysis and hypothesis test methods. } \\
\text { If no specific statistical method is described in abstract, "not } \\
\text { reported" is recorded. }\end{array}$ \\
\hline & $\begin{array}{l}\text { Primary } \\
\text { outcome }\end{array}$ & $\begin{array}{l}\text { Any addition, deletion or replacement of primary outcomes clearly } \\
\text { specified by authors. }\end{array}$ \\
\hline & Sample size & $\begin{array}{l}\text { Increase or decrease in sample size. For RCT /CCT of different } \\
\text { follow-up length, the corresponding sample size at reporting } \\
\text { time point is recorded }\end{array}$ \\
\hline & $\begin{array}{l}\text { Quantitative } \\
\text { outcome }\end{array}$ & $\begin{array}{l}\text { Any change in all quantitative results reported in abstract. If cross- } \\
\text { group comparisons are made, only effect size are compared. If } \\
\text { effect size is absent, all quantitative results reported in the } \\
\text { abstract are compared. }\end{array}$ \\
\hline & $\begin{array}{l}\text { Significance of } \\
\text { results }\end{array}$ & $\begin{array}{l}\text { Any change in direction of significance of outcomes reported in } \\
\text { abstract. Significance is evaluated at } 5 \% \text { level for between-arm } \\
\text { comparison for the outcomes reported in abstracts. When the } \\
\text { effect estimate, } 95 \% \text { confidence interval or } p \text { value is not } \\
\text { reported but authors state the outcomes as significant, we still } \\
\text { define it significant. }\end{array}$ \\
\hline & Conclusions & $\begin{array}{l}\text { For comparison between groups, any change of positiveness is } \\
\text { recorded. When no comparison is made, dramatic change of the } \\
\text { main founding (e.g. Prevalence, severity of case reports) is } \\
\text { recorded. }\end{array}$ \\
\hline
\end{tabular}


Table 2 Abstracts and full publications demographics and FPP

\begin{tabular}{|c|c|c|c|c|c|}
\hline Characteristics & Category & $\begin{array}{l}\text { All abstracts } \\
\mathrm{N}=850 \\
\mathrm{n}(\%)^{\dagger}\end{array}$ & $\begin{array}{l}\text { Published } \\
\mathrm{N}=309 \\
\mathrm{n}(\%)^{+}\end{array}$ & $\begin{array}{l}\text { Non-published } \\
\mathrm{N}=541 \\
\mathrm{n}(\%)^{\dagger}\end{array}$ & $\operatorname{FPP}(\%)^{\ddagger}$ \\
\hline \multirow[t]{2}{*}{ Presentation type } & Poster & $754(88.7)$ & $243(78.6)$ & $511(94.5)$ & 32.2 \\
\hline & Oral & 96 (11.3) & 66 (21.4) & $30(5.5)$ & 68.8 \\
\hline \multirow[t]{2}{*}{ Study type } & Basic research & $276(32.5)$ & $115(37.2)$ & $161(29.8)$ & 41.7 \\
\hline & Clinical study & 574 (67.5) & $194(62.8)$ & 380 (70.2) & 33.8 \\
\hline \multirow[t]{3}{*}{ Number of authors } & $<4$ & $291(34.2)$ & $81(26.2)$ & $210(38.8)$ & 27.8 \\
\hline & 4 to 7 & $502(59.1)$ & 201 (65.1) & 301 (55.7) & 40.0 \\
\hline & $>7$ & $57(6.7)$ & $27(8.7)$ & $30(5.5)$ & 47.4 \\
\hline \multirow[t]{5}{*}{ First author continent } & Europe & $556(65.4)$ & $216(70.0)$ & $340(62.8)$ & 38.9 \\
\hline & Asia & 226 (26.6) & 67 (21.6) & 159 (29.4) & 29.6 \\
\hline & South America & $35(4.1)$ & $13(4.2)$ & $22(4.1)$ & 37.1 \\
\hline & North America & $28(3.3)$ & $13(4.2)$ & $15(2.8)$ & 46.4 \\
\hline & Africa, Australia, Oceania & $5(0.6)$ & $0(0.0)$ & $5(0.9)$ & 0.0 \\
\hline \multirow[t]{2}{*}{ Multiple affiliations } & No & 399 (46.9) & $113(36.6)$ & $286(52.9)$ & 28.3 \\
\hline & Yes & $451(53.1)$ & $196(63.4)$ & 255 (47.1) & 43.5 \\
\hline \multirow[t]{2}{*}{ International collaboration } & No & 743 (87.4) & 249 (80.6) & 494 (91.3) & 33.5 \\
\hline & Yes & 107 (12.6) & 60 (19.4) & $47(8.7)$ & 56.1 \\
\hline \multirow[t]{2}{*}{ Statistical test } & No & 483 (56.8) & $130(42.0)$ & $353(65.2)$ & 26.9 \\
\hline & Yes & 367 (43.2) & 179 (58.0) & 188 (34.8) & 48.8 \\
\hline \multirow[t]{3}{*}{ Significance of result } & Non-significant & $78(9.2)$ & 36 (11.7) & $42(7.8)$ & 46.2 \\
\hline & Significant & $289(34.0)$ & $143(46.3)$ & $146(27.0)$ & 49.5 \\
\hline & Not-reported & $483(56.8)$ & $130(42.0)$ & $353(65.2)$ & 26.9 \\
\hline
\end{tabular}

† Proportion of abstracts with different characteristics in all $(\mathrm{N}=850)$, published $(\mathrm{N}=309)$ and non-published $(\mathrm{N}=541)$ abstracts. † FPP of abstracts by different abstract characteristics. 
Table 3 FPP of different study types

\begin{tabular}{|c|c|c|c|c|}
\hline Category & $\begin{array}{l}\text { All abstracts } \\
\mathrm{N}=850 \\
\mathrm{n}(\%)^{+}\end{array}$ & $\begin{array}{l}\text { Published } \\
\mathrm{N}=309 \\
\mathrm{n}(\%)^{+}\end{array}$ & $\begin{array}{l}\text { Non-published } \\
\mathrm{N}=541 \\
\mathrm{n}(\%)^{+}\end{array}$ & $\operatorname{FPP}(\%)^{\ddagger}$ \\
\hline \multicolumn{5}{|l|}{ Basic research } \\
\hline in vivo & 120 (14.9) & $54(17.5)$ & $66(12.2)$ & 45.0 \\
\hline in vitro & $75(9.3)$ & 27 (8.7) & 48 (8.9) & 36.0 \\
\hline others & $73(9.1)$ & $32(10.4)$ & 41 (7.6) & 43.8 \\
\hline narrative review & $8(1.0)$ & $2(0.6)$ & $6(1.1)$ & 25.0 \\
\hline \multicolumn{5}{|l|}{ Clinical study } \\
\hline RCT & 62 (7.7) & 41 (13.3) & 21 (3.9) & 66.1 \\
\hline CCT & $171(21.2)$ & 74 (23.9) & 97 (17.9) & 43.3 \\
\hline case report/series & 136 (16.9) & $21(7.0)$ & $115(21.3)$ & 15.4 \\
\hline cohort & $113(14.0)$ & $26(8.4)$ & $87(16.1)$ & 23.0 \\
\hline cross-sectional & $65(8.1)$ & $24(7.8)$ & $41(7.6)$ & 36.9 \\
\hline case-control & $4(0.5)$ & $3(1.0)$ & $1(0.2)$ & 75.0 \\
\hline systematic review & $16(2.0)$ & $5(1.6)$ & $11(2.0)$ & 31.3 \\
\hline narrative review & $7(0.9)$ & $0(0.0)$ & $7(1.3)$ & 0.0 \\
\hline
\end{tabular}

+ Proportion of abstracts with different study types in all $(\mathrm{N}=850)$, published $(\mathrm{N}=309)$ and non-published $(\mathrm{N}=541)$ abstracts.

$¥$ FPP of abstracts by different abstract characteristics. 
Table 4 The number and proportion of discrepancies between abstracts and full publications

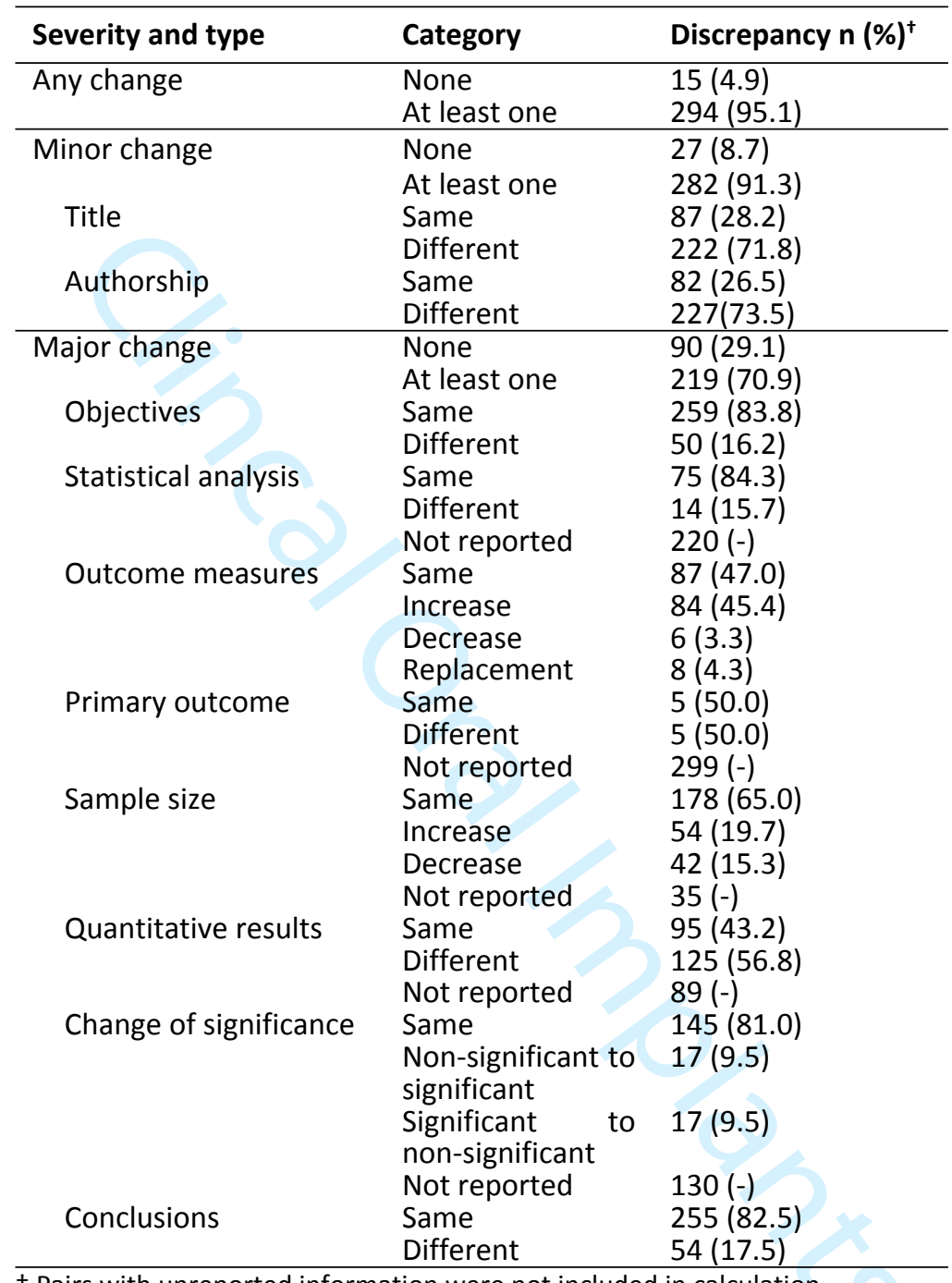

† Pairs with unreported information were not included in calculation. 
Table 5 Discrepancies between abstracts and full publications for RCT/CCT

\begin{tabular}{lll}
\hline Type & Category & Discrepancy $\mathbf{n}\left(\%^{+}\right)$ \\
\hline Registration ID & Same & $3(100.0)$ \\
& Different & $0(0.0)$ \\
Blinding & Not reported & $112(-)$ \\
& Same & $9(100.0)$ \\
& Different & $0(0.0)$ \\
Follow-up length & Not reported & $106(-)$ \\
& Same & $88(81.5)$ \\
& Different & $20(18.5)$ \\
Harms & Not reported & $7(-)$ \\
& Same & $13(59.1)$ \\
& Different & $9(40.9)$ \\
& Not reported & $93(-)$ \\
\hline
\end{tabular}

† Pairs with unreported information were not included in calculation. 
Table 6 Univariate and multivariable linear regression derived coefficients $(B)$ and 95\% confidence intervals, with DS as the dependent variable for the included 309 pairs. VIF, variance inflation factor.

\begin{tabular}{|c|c|c|c|c|c|c|c|c|c|}
\hline \multirow{2}{*}{ Predictors } & \multirow{2}{*}{ Category/Unit } & \multicolumn{3}{|l|}{ Univariable } & \multicolumn{5}{|c|}{ Multivariable $^{\dagger}$} \\
\hline & & B & $95 \% \mathrm{Cl}$ & $P$ value & $B$ & $95 \% \mathrm{Cl}$ & Tolerance & VIF & $p$ value \\
\hline \multirow{2}{*}{$\begin{array}{l}\text { Time lapse } \\
\text { Presentation type }\end{array}$} & 1 month & 0.06 & $(0.04,0.08)$ & $<0.001$ & 0.06 & $(0.04,0.08)$ & 0.99 & 1.01 & $<0.001$ \\
\hline & $\begin{array}{l}\text { Poster } \\
\text { Oral }\end{array}$ & $\begin{array}{l}\text { Reference } \\
-0.72\end{array}$ & $(-166023)$ & 137 & & & & & \\
\hline \multirow[t]{2}{*}{ Study Type } & Basic research & Reference & $1.00,0.201$ & 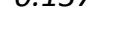 & Reference & & & & \\
\hline & Clinical study & 1.46 & $(0.67,2,24)$ & $<0.001$ & 1.30 & $(0.52,2.08)$ & 0.94 & 1.07 & 0.001 \\
\hline \multirow[t]{3}{*}{ Number of authors } & $<4$ & Reference & & & & & & & \\
\hline & 4 to 7 & 0.89 & $(0.00,1.79)$ & 0.051 & & & & & \\
\hline & $>7$ & 0.22 & $(-1.29,1.73)$ & 0.773 & & & & & \\
\hline \multirow[t]{4}{*}{ Continent } & Europe & Reference & & & Reference & & & & \\
\hline & Asia & -1.10 & $(-2.05,-0.15)$ & 0.023 & -0.87 & $(-1.77,0.04)$ & 0.94 & 1.07 & 0.062 \\
\hline & South America & 0.61 & $(-1.33,2.54)$ & 0.538 & 0.31 & $(-1.52,2.14)$ & 0.94 & 1.06 & 0.74 \\
\hline & North America & -1.24 & $(-3.18,0.70)$ & 0.209 & -0.22 & $(-2.09,1.64)$ & 0.98 & 1.02 & 0.814 \\
\hline \multirow[t]{2}{*}{ Multiple affiliations } & No & Reference & & & & & & & \\
\hline & Yes & -0.08 & $(-0.89,0.73)$ & 0.846 & & & & & \\
\hline \multirow[t]{2}{*}{ International collaboration } & No & Reference & & & & & & & \\
\hline & Yes & -0.34 & $(-1.32,0.65)$ & 0.503 & & & & & \\
\hline \multirow[t]{2}{*}{ Significance of result } & Non-significant & Reference & & & & & & & \\
\hline & Significant & 0.515 & $(-0.76,1.79)$ & 0.427 & & & & & \\
\hline \multirow[t]{2}{*}{ Statistical test } & No & Reference & & & & & & & \\
\hline & Yes & 0.43 & $(-0.35,1.22)$ & 0.281 & & & & & \\
\hline \multirow[t]{3}{*}{ Funding } & Industries & Reference & & & & & & & \\
\hline & Other sources & -0.52 & $(-1.68,0.64)$ & 0.377 & & & & & \\
\hline & Unfunded/unreported & -0.94 & $(-1.10,0.11)$ & 0.078 & & & 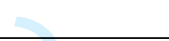 & & \\
\hline
\end{tabular}

† For multivariable analysis, constant $=3.382, R^{2}=0.142$, adjusted $R^{2}=0.128, P<0.001$. 
Table 7 Univariate and multivariable linear regression derived coefficients (B) and 95\% confidence intervals, with the number of discrepancies as the dependent variable for the included 309 pairs. VIF, variance inflation factor.

\begin{tabular}{|c|c|c|c|c|c|c|c|c|c|}
\hline \multirow{2}{*}{ Predictors } & \multirow{2}{*}{ Category } & \multicolumn{3}{|c|}{ Univariable } & \multicolumn{5}{|c|}{ Multivariable $^{\dagger}$} \\
\hline & & B & $95 \% \mathrm{Cl}$ & $p$ value & B & $95 \% \mathrm{Cl}$ & Tolerance & VIF & $p$ value \\
\hline \multirow{3}{*}{$\begin{array}{l}\text { Time lapse } \\
\text { Presentation type }\end{array}$} & & 0.04 & $(0.02,0.05)$ & $<0.001$ & 0.04 & $(0.02,0.05)$ & 1.00 & 1.00 & $<0.001$ \\
\hline & Poster & Reference & & & & & & & \\
\hline & $\begin{array}{l}\text { Oral } \\
\text { Basic research }\end{array}$ & $\begin{array}{l}-0.45 \\
\text { Reference }\end{array}$ & $(-0.97,0.06)$ & 0.085 & & & & & \\
\hline Study Type & Clinical study & 0.68 & $(0.25,1.11)$ & 0.002 & 0.66 & $(0.26,1.08)$ & 1.00 & 1.00 & 0.002 \\
\hline \multirow[t]{3}{*}{ Number of authors } & $<4$ & Reference & & & & & & & \\
\hline & 4 to 7 & 0.48 & $(-0.01,0.97)$ & 0.057 & & & & & \\
\hline & $>7$ & 0.15 & $(-0.68,0.98)$ & 0.725 & & & & & \\
\hline \multirow[t]{4}{*}{ Continent } & Europe & Reference & & & & & & & \\
\hline & Asia & -0.49 & $(-1.01,0.03)$ & 0.067 & & & & & \\
\hline & South America & 0.13 & $(-0.22,0.49)$ & 0.458 & & & & & \\
\hline & North America & -0.34 & $(-0.87,0.19)$ & 0.211 & & & & & \\
\hline \multirow[t]{2}{*}{ Multiple affiliations } & No & Reference & & & & & & & \\
\hline & Yes & -0.12 & $(-0.56,0.33)$ & 0.608 & & & & & \\
\hline \multirow{2}{*}{ International collaboration } & No & Reference & & & & & & & \\
\hline & Yes & -0.19 & $(-0.73,0.35)$ & 0.49 & & & & & \\
\hline \multirow[t]{3}{*}{ Significance of result } & Non-significant & Reference & & & & & & & \\
\hline & Significant & 0.18 & $(-0.52,0.88)$ & 0.607 & & & & & \\
\hline & Not reported & -0.05 & $(-0.75,0.66)$ & 0.89 & & & & & \\
\hline \multirow[t]{2}{*}{ Statistical test } & No & Reference & & & & & & & \\
\hline & Yes & 0.20 & $(-0.24,0.63)$ & 0.372 & & & & & \\
\hline \multirow[t]{3}{*}{ Funding } & Industries & Reference & & & & & & & \\
\hline & Other sources & -0.24 & $(-0.87,0.40)$ & 0.464 & & & & & \\
\hline & Unfunded/unreported & -0.50 & $(-1.08,0.07)$ & 0.085 & & & & & \\
\hline
\end{tabular}

+ For multivariable analysis, constant $=2.243, \mathrm{R}^{2}=0.131$, adjusted $\mathrm{R}^{2}=0.125, \mathrm{P}<0.001$. 


\section{Figure legend}

Figure 1 Kaplan Meier plots showing time lapse from abstract presentation to full publication, overall and by various abstract characteristics.

footnote: Only characteristics with significant log-rank test and valid proportional hazard assumption are shown. The top left corner of each picture shows log-rank test $p$ value and hazard ratio (HR) as well as its $95 \% \mathrm{Cl}, p$ value in Cox regression modelling. $\boldsymbol{a}$. for all abstracts; $\boldsymbol{b}$. by presentation type; $\boldsymbol{c}$. by study type; $\boldsymbol{d}$. by whether there were multiple affiliations; $e$. by whether there was international collaboration; $f$. by whether there was statistical test. 


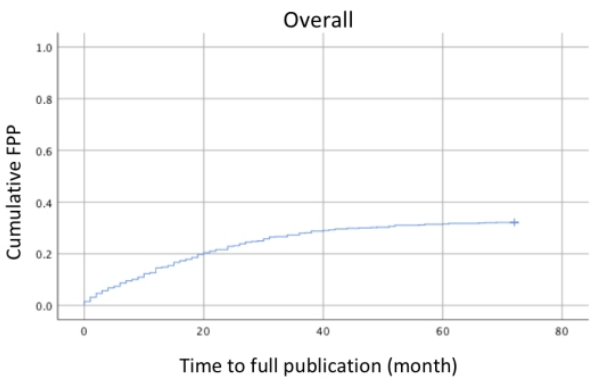

(a)

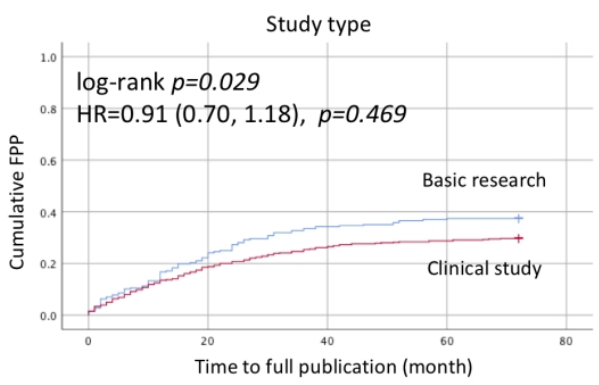

(c)

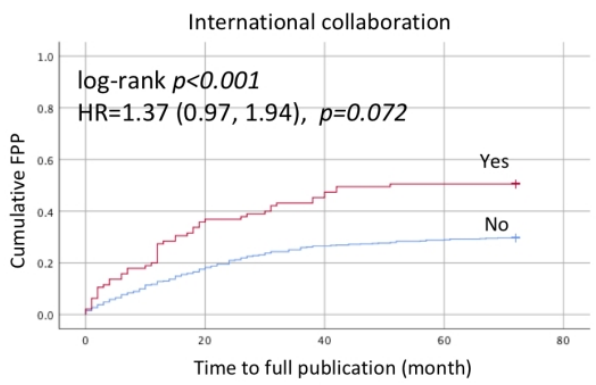

(e)

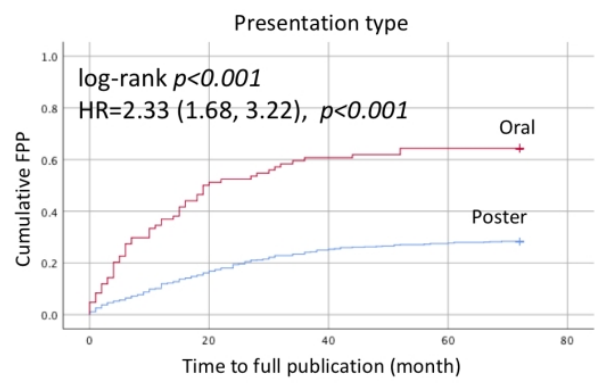

(b)

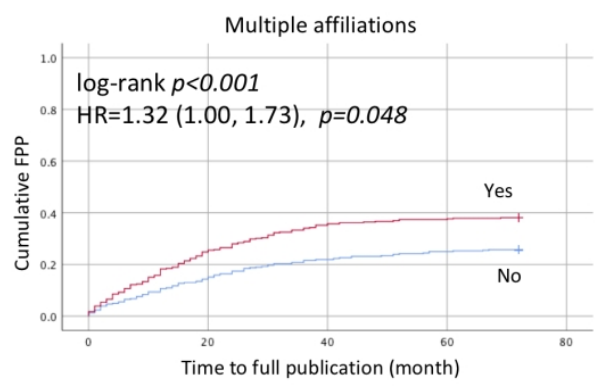

(d)

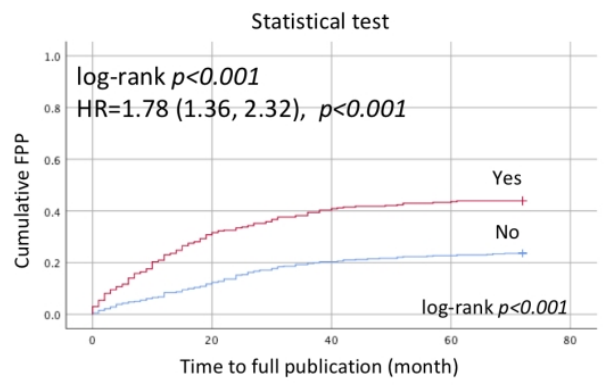

(f)

Figure 1 Kaplan Meier plots showing time lapse from abstract presentation to full publication, overall and by various abstract characteristics

$171 \times 182 \mathrm{~mm}(300 \times 300 \mathrm{DPI})$ 